\title{
Distorted Odor Maps in the Olfactory Bulb of Semaphorin 3A-Deficient Mice
}

\author{
Masahiko Taniguchi, ${ }^{1,5}$ Hiroshi Nagao, ${ }^{2}$ Yuji K. Takahashi, ${ }^{2}$ Masahiro Yamaguchi, ${ }^{2}$ Sachiko Mitsui, ${ }^{3}$ Takeshi Yagi, ${ }^{4,5}$ \\ Kensaku Mori, ${ }^{2}$ and Takao Shimizu ${ }^{1,5}$ \\ Departments of ${ }^{1}$ Biochemistry and Molecular Biology and ${ }^{2}$ Physiology, Graduate School of Medicine, The University of Tokyo, Hongo, Bunkyo-ku, Tokyo \\ 113-0033, Japan, ${ }^{3}$ Laboratory for Neurobiology of Synapse, Brain Science Institute, RIKEN, Wako, Saitama 351-0198, Japan, ${ }^{4}$ KOKORO Biology Group, \\ Laboratories of Integrated Biology, Graduated School of Frontier Biosciences, Osaka University, Yamadaoka 565-0871, Japan, and ${ }^{5}$ Core Research for \\ Evolutional Science and Technology, Japan Science and Technology Corporation, Kyoto 604-0847, Japan
}

Semaphorin 3A (Sema3A) repels growing olfactory axons that express neuropilin-1 (NP-1), a receptor for Sema3A. The Sema3Amediated axon guidance seems to be essential for the formation of the glomerular sensory map in the olfactory bulb (OB). To understand whether and how Sema3A is involved in sensory map formation, we examined the glomerular map in the OB of adult Sema3A-deficient mice. In wild-type mice, NP-1-positive glomeruli form the lateral and medial bands and avoid the anteromedial and ventral regions of the OB. In the Sema3A-deficient OB, NP-1-positive glomeruli spread over the entire OB, and we consistently found the ectopic arrangement of NP-1-positive glomeruli in the anteromedial and ventral regions. In addition, a specific subset of NP-1-negative and olfactory cell adhesion molecule-positive glomeruli, especially those in the anteromedial region, disappeared from the mutant $\mathrm{OB}$. These results show a critical role for Sema3A in the spatial arrangement of glomeruli in the OB. Optical imaging from the dorsal OB showed that the distorted glomerular map conserved molecular-feature domains. However, the positions of the domains were shifted, which suggests a secondary rearrangement of the glomerular map in the Sema3A-deficient OB.

Key words: semaphorin; neuropilin; OCAM; olfactory bulb; glomerular sensory map; optical imaging

\section{Introduction}

Individual olfactory sensory neurons express a single type of odorant receptor (Buck, 1996; Mombaerts, 1999). Sensory neurons expressing a given type of odorant receptor converge their axons onto a few topographically fixed glomeruli in the olfactory bulb (OB). Individual glomeruli presumably represent a single type of odorant receptor. Therefore, the spatial arrangement of the glomeruli at the $\mathrm{OB}$ surface provides an odorant-receptor map (Mori et al., 1999). The glomeruli are formed primarily during perinatal and early postnatal periods (Valverde et al., 1992), and the glomerular sensory map keeps a stereotyped spatial organization despite the continuous turnover of olfactory axons throughout animal's life (Wang et al., 1998; Royal and Key, 1999). Molecular mechanisms for the formation and maintenance of the precise glomerular sensory map remain primarily unknown.

The axon guidance to their specific targets plays a crucial role in the formation of patterned neuronal connections; thus, it is essential for the establishment of the topographic sensory maps in the brain. Several groups of molecules, such as semaphorins,

\footnotetext{
Received 0ct. 21, 2002; revised Dec. 2, 2002; accepted Dec. 4, 2002.

This work was supported by grants-in-aid for Encouragement of Young Scientists, for Scientific Research on Priority Area(A) (Maturation and Specialization of Neural Circuits), and for Scientific Research on Priority Area(C) (Advanced Brain Science Project) from the Ministry of Education, Culture, Sports, Science and Technology, Japan (M.T.); for Creative Scientific Research (K.M.) from the Japan Society for the Promotion of Science, Japan; and for Yamanouchi Foundation for Research on Metabolic Disorders (M.T.). We thank Dr. Yoshihiro Yoshihara for critical reading of this manuscript and Dr. Peter Mombaerts for the gift of P2-IRES-tau-lacZ mice.

Correspondence should be addressed to Dr. Kensaku Mori, Department of Physiology, Graduate School of Medicine, The University of Tokyo, 7-3-1 Hongo, Bunkyo-ku, Tokyo 113-0033, Japan. E-mail:moriken@m.u-tokyo.ac.jp. Copyright $\odot 2003$ Society for Neuroscience $\quad 0270-6474 / 03 / 231390-08 \$ 15.00 / 0$
}

ephrins, netrins, and slits, have been reported to repel or attract the growing axons that express their respective receptors (Chisholm and Tessier-Lavigne, 1999).

Semaphorins secreted and transmembrane proteins containing a semaphorin domain are found in both vertebrates and invertebrates (Semaphorin Nomenclature Committee, 1999; Nakamura et al., 2000; Raper, 2000). Semaphorin 3A (Sema3A) was first identified on the basis of its ability to induce the collapse of the growth cones of dorsal root ganglion cells (Luo et al., 1993). Sema3A-deficient mice showed a severe abnormality in the axonal projection pattern in the peripheral nervous system during embryogenesis (Taniguchi et al., 1997).

Sema3A is also expressed in the olfactory system (Giger et al., 1996, 1998; Pasterkamp et al., 1998). In the olfactory nerve layer (ONL) of the developing $\mathrm{OB}$, Sema3A is expressed in ensheathing cells that are localized at the anteromedial and ventral regions (Crandall et al., 2000; Schwarting et al., 2000). Sema3A repels the growing olfactory axons that express neuropilin-1 (NP-1), a Sema3A receptor (Kawakami et al., 1996; He and TessierLavigne, 1997; Kitsukawa et al., 1997; Kobayashi et al., 1997; Kolodkin et al., 1997). In adults, the NP-1-expressing olfactory axons project selectively to the glomeruli within the medial and lateral bands of the $\mathrm{OB}$ and avoid the Sema3A-expressing regions (Pasterkamp et al., 1998; Nagao et al., 2000). In addition, Schwarting et al. (2000) showed that in the Sema3A-deficient embryos, NP-1-expressing olfactory axons projected to the nontarget regions. These results suggest that Sema3A-mediated olfactory axon guidance plays a key role in sensory map formation.

Because the Sema3A-deficient mice used in previous studies died during the perinatal period (Schwarting et al., 2000), it was 
impossible to analyze the spatial pattern of the mature glomerular sensory map in the Sema3A-deficient mice. We have previously generated Sema3A-deficient mice that survive to adulthood (Taniguchi et al., 1997). In the present study, we examined the spatial pattern of the glomerular sensory map and the odorantevoked activity map in the OB of adult Sema3A-deficient mice.

\section{Materials and Methods}

Mice. The Sema3A-deficient mice used in this study had the C57BL/6 genetic background and were genotyped as described previously (Taniguchi et al., 1997). P2-internal ribosome entry site (IRES)-tau-lacZ mice were a gift from Dr. P. Mombaerts (The Rockefeller University, New York, NY) (Mombaerts et al., 1996). Studies were performed in accordance with the guidelines for animal experiments at the University of Tokyo.

Immunohistochemistry. Adult mice were deeply anesthetized with pentobarbital sodium and perfused with $0.1 \mathrm{M}$ phosphate buffer (PB), $\mathrm{pH}$ 7.4 , followed by $4 \%$ paraformaldehyde in PB. Brains were postfixed in $4 \%$ paraformaldehyde for $2 \mathrm{hr}$ and then kept overnight in cold $\mathrm{PB}$ containing $20 \%$ sucrose. Coronal sections $(20 \mu \mathrm{m})$ through the OB were cut with a cryostat microtome. The sections were permeabilized with $0.2 \%$ Triton X-100 in Tris-buffered saline (TBS), blocked with TBS containing $10 \%$ normal goat serum (Invitrogen, Carlsbad, CA), and incubated with primary antibodies overnight at room temperature. The primary antibodies used were rat anti-neural cell adhesion molecule (NCAM) monoclonal antibody (MAB310, 1/200 dilution; Chemicon, Temecula, CA), rabbit anti-olfactory cell adhesion molecule (OCAM) polyclonal antibody (1/1000 dilution) (Yoshihara et al., 1997), rabbit anti-NP-1 polyclonal antibody (1/150 dilution), and goat anti- $\beta$-galactosidase polyclonal antibody (4600-1409, 1/500 dilution; Biogenesis, Poole, UK). Sections were incubated with labeled anti-rat secondary antibody (Alexa Fluor 488, A-11006; Molecular Probes, Eugene, OR) for NCAM staining, with labeled anti-rabbit secondary antibody (Alexa Fluor 546, A-11035; Molecular Probes) for OCAM and NP-1 staining, and with labeled antigoat secondary antibody (Alexa Fluor 350, A-21081; Molecular Probes) for $\beta$-galactosidase staining.

Anti-NP-1 antibody production. Anti-NP-1 antibody was produced according to the method described by Kolodkin et al. (1997). Briefly, a fragment of mouse NP-1, corresponding to amino acids C583-I856, was cloned into the p $\mathrm{TrcHis}$ vector (Invitrogen). A six-histidine-tagged NP-1 fragment was produced in Escherichia coli and purified using a nickel column. Rabbits were immunized with the NP-1 fragment $(1.1 \mathrm{mg} / \mathrm{rab}-$ bit). Western blotting of adult mouse brain homogenate showed that the antibody primarily recognized the $120 \mathrm{kDa}$ molecule, corresponding to $\mathrm{NP}-1$ in size. Immunohistochemical labeling of the OB sections with the antibody showed a characteristic staining pattern that has been reported previously with the characterized anti-NP-1 antibody (Nagao et al., 2000).

Standardized unrolled map. The preparation of standardized unrolled flattened map was as described previously (Nagao et al., 2000). Briefly, the ring of labeled and unlabeled glomeruli from each photomicrograph of the OB section was traced on a sheet. The ring of glomeruli was flattened by opening it at its ventral edge. The unrolled map of glomeruli was constructed by aligning flattened traces of consecutive sections using as a reference line the dorsal edge of the mitral cell layer (MCL). Samples of sections for the immunohistochemistry were obtained at $100 \mu \mathrm{m}$ intervals.

Optical imaging of intrinsic signals. Adult mice were anesthetized with medetomidine $(0.5 \mathrm{mg} / \mathrm{kg})$, ketamine $(22.5 \mathrm{mg} / \mathrm{kg})$, and pentothal sodium $(25 \mathrm{mg} / \mathrm{kg})$. A $4 \times 2 \mathrm{~mm}$ area of skull overlying the dorsal surface of the right $\mathrm{OB}$ or both $\mathrm{OBs}$ were removed. Agarose gel was mounted on one or both OBs and covered with a cover glass. Images of reflected light from the dorsal surface of the $\mathrm{OB}$ were collected using a CCD camera (CS8310; Tokyo Electronic Industry Co., Ltd., Tokyo, Japan) with a tandem-lens macroscope arrangement, digitized, and stored on a Pentium processor hard drive using a frame-grabber board (Pulsar; Matrox Graphics, Dorval, Quebec, Canada). The images had a spatial resolution of $320 \times 240$ pixels (after $2 \times 2$ binning). In most experiments, we imaged a $4.2 \times 3.14 \mathrm{~mm}$ region, giving a pixel size of $13.2 \mu \mathrm{m}^{2}$. Intrinsic signals were imaged with $705 \mathrm{~nm}$ wavelength light. For each recording trial, data were collected for $8 \mathrm{sec}$ with a frame length of $500 \mathrm{msec}$ (16 frames per trial). Odorant stimulation was applied from the beginning of the 4 th to the end of the 16 th frame. Odorant stimulation was performed by placing an odorant-containing test tube within $5 \mathrm{~mm}$ of the animal's nostril. Odorant-response maps were obtained by dividing the magnitude of signals acquired during stimulation (in most cases, frames 1016) by that acquired before stimulation (frames 1-2).

\section{Results}

\section{Decrease in the number of glomeruli in the Sema3A-deficient bulb}

As reported previously (Taniguchi et al., 1997), the size of the OB of adult Sema3A-deficient mice was smaller than that of the wildtype mice (Fig. $1 A, B$ ). This could be attributable to the alteration in the intrinsic structure of the $\mathrm{OB}$ or the decrease in the number of constituent glomerular modules (Shepherd and Greer, 1998; Mori et al., 1999). Microscopic observations of Nissl-stained sections showed that the Sema3A-deficient $\mathrm{OB}(n=5)$ had a normal layered structure (Fig. 1D); it consisted of ONL, glomerular layer (GL), external plexiform layer (EPL), MCL, internal plexiform layer (IPL), and granule cell layer (GCL). Except for a change in the shape and volume of the deep layers (EPL, MCL, IPL, and GCL), and for a tendency toward fewer glomeruli in the dorsal region and more glomeruli in the ventral region (Fig. 1D), the overall cytoarchitecture of each layer was similar to that of the wild-type OB (Fig. 1C). For example, the GL of the Sema3Adeficient $O B$ consisted of an array of spherical neuropils (glomeruli) that were surrounded by the somata of periglomerular cells and external tufted cells (Fig. 1D).

To examine the possible decrease in the number of glomeruli in the Sema3A-deficient OB, we counted the total number of glomeruli observed in the coronal sections ( $20 \mu \mathrm{m}$ in thickness) that were sampled at $100 \mu \mathrm{m}$ intervals from the anterior tip to the posterior end of the OB. As listed in Table 1, the total number of glomeruli in adult Sema3A-deficient OBs decreased to $81 \pm 5 \%$ (SD; $n=8$ littermate pairs) of that of the wild-type OB. Therefore, the decline in the size of the $\mathrm{OB}$ is presumably attributable to both a decrease in the number of glomeruli and a decrease in the volume of the deeper layers.

The decrease in the number of glomeruli in the Sema3Adeficient $\mathrm{OB}$ might be attributable either to the inability to form a specific subset of glomeruli or to the fusion of more than two different glomeruli into one. The fusion might give rise to glomeruli that receive inputs from multiple types of odorant receptors. To examine whether individual glomeruli in the Sema3Adeficient $\mathrm{OB}$ receive converging olfactory axons originating from sensory neurons expressing the same type of odorant receptor, we made Sema3A-deficient mice and littermate wild-type mice having the P2-IRES-tau-lacZ locus (Mombaerts et al., 1996).

Immunohistochemical observations of the $\mathrm{OB}$ sections using anti- $\beta$-galactosidase (LacZ) antibody showed that in both the wild-type mice $(n=4)$ and Sema3A-deficient mice $(n=4)$, labeled olfactory axons from P2-expressing sensory neurons converged onto a few glomeruli (Fig. $1 E, F$ ). In the left $\mathrm{OB}$ of the wild-type mice, we typically observed two $\mathrm{P} 2$ glomeruli at the ventrolateral region and one $\mathrm{P} 2$ glomerulus at the ventromedial region (Figs. 1E, 2C, 3C) (Schaefer et al., 2001). In the left OB of the Sema3A-deficient mice, we found the same number of P2 glomeruli at approximately similar positions, two P2 glomeruli at the ventrolateral region, and one $\mathrm{P} 2$ glomerulus at the ventromedial region (Figs. $1 F, 2 D, 3 D$ ). The $\mathrm{P} 2$ glomeruli appeared to be occupied exclusively with LacZ-expressing olfactory axons, sug- 

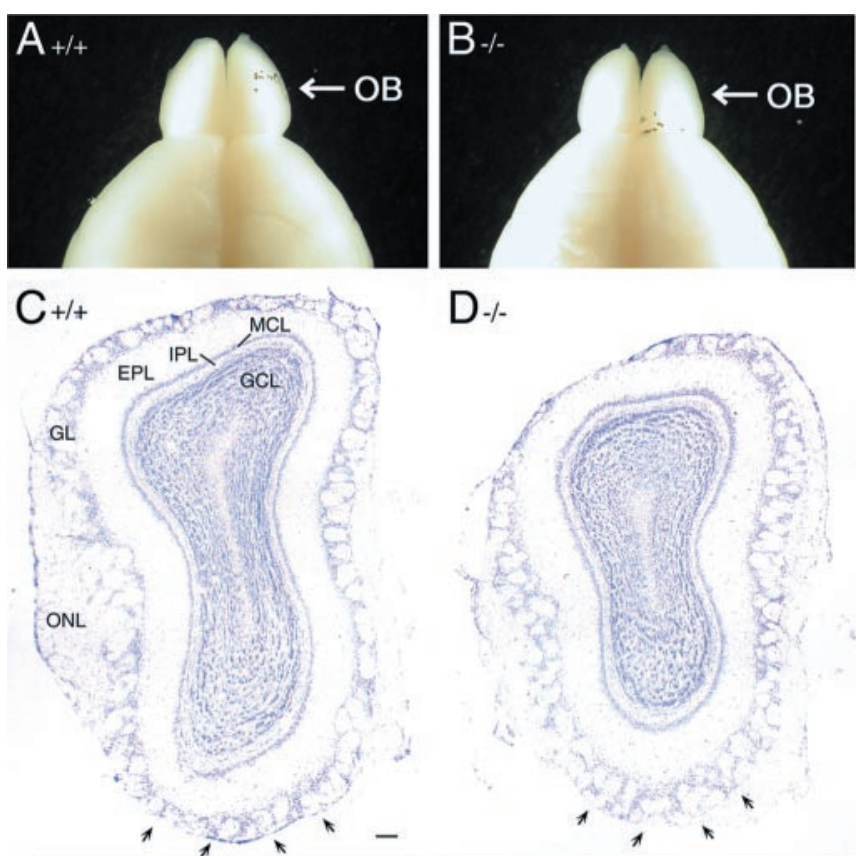

D $\%$
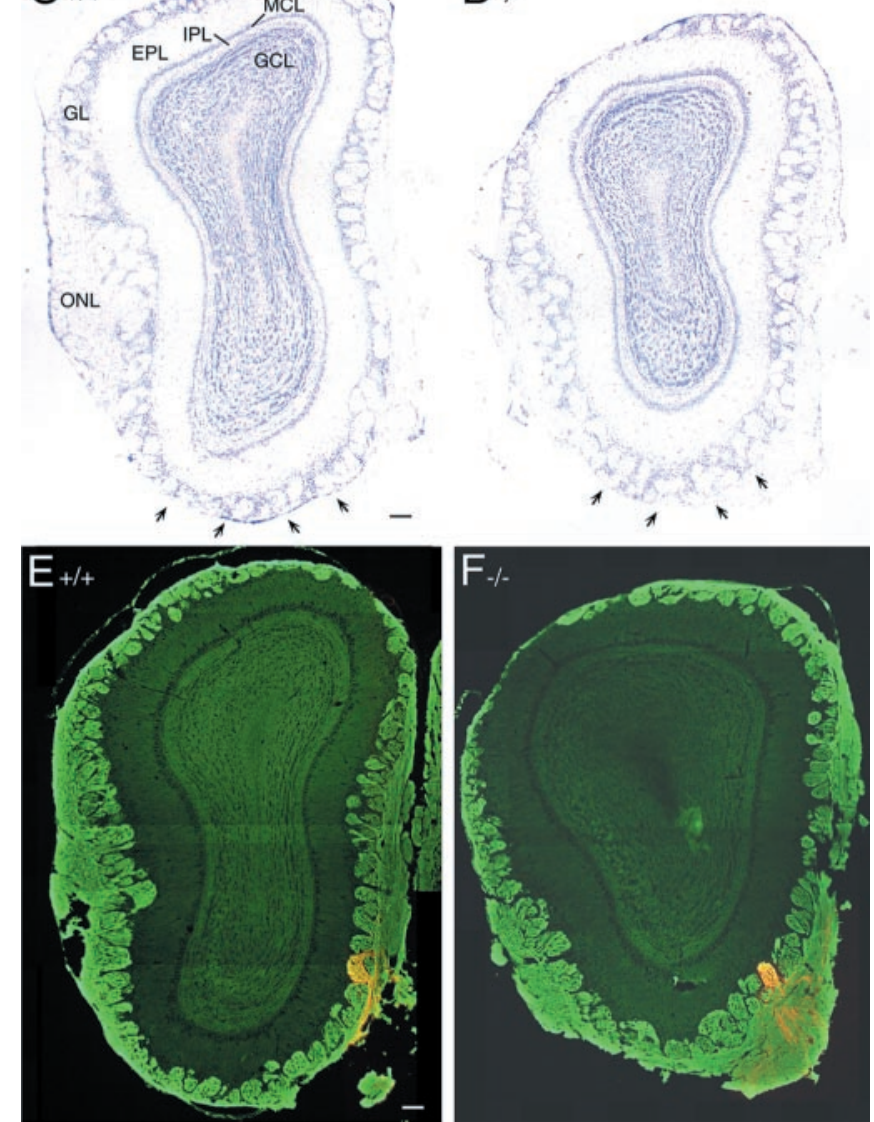

Figure 1. Comparison of the layered structure and glomeruli between adult wild-type and Sema3A-deficient OBs. $A, B$, Dorsal view of the OBs of adult wild-type mice $(A,+/+)$ and littermate Sema3A-deficient mice $(B,-/-)$. Both the wild-type and the Sema3A-deficient OBs had an ellipsoidal shape, but the size of the Sema3A-deficient OB was smaller than the wild-type OB.C, D, Nissl staining of the coronal sections through the $O B$ s of adult wild-type mice $(C,+/+)$ and littermate Sema3A-deficient mice $(D,-/-)$. Sema3A-deficient OB shows a distinct $G L$. Although the $G L$ in the ventral part of the wild-type $0 B$ was one glomerulus thick ( $C$, arrows), a pile-up of two or more glomeruli was typically observed in the ventral region of the Sema3A-deficient mice ( $D$, arrows). Dorsal is up, and medial is to the right. Scale bar, $100 \mu \mathrm{m}$. $E, F$, Immunostaining of coronal sections through the $0 \mathrm{Bs}$ of adult wild-type mice $(E,+/+)$ and littermate Sema3A-deficient mice $(F,-/-)$ that have the P2-IRES-tau-lacZlocus. All glomeruli were labeled with anti-NCAM antibody ( green), whereas $\mathrm{P} 2$ glomeruli were labeled by anti- $\beta$ galactosidase antibody (red). Both the wild-type and the Sema3A-deficient OB showed glomerular convergence for $\mathrm{P} 2$ glomeruli $(E, F$, yellow glomeruli). Dorsal is up, and medial is to the right. Scale bar, $100 \mu \mathrm{m}$.

gesting that the glomerular convergence pattern does not change significantly, at least for P2 glomeruli in the Sema3A-deficient OB. This does not exclude the possibility that the glomerular convergence pattern might be disturbed for glomeruli representing odorant receptors other than $\mathrm{P} 2$ in the Sema3A-deficient mice.

Immunohistochemical examination of the ONL and GL with anti-NP-1 and anti-OCAM antibodies showed that P2-positive olfactory axons expressed OCAM but did not express NP-1 in both wild-type and Sema3A-deficient OBs. All of the P2 glomer-
Table 1. Comparison of the number of glomeruli between Sema3A-deficient OB and littermate wild-type $\mathrm{OB}$

\begin{tabular}{|c|c|c|c|}
\hline Mice & Total glomeruli & $\mathrm{NP}-1^{+}$glomeruli & NP-1 ${ }^{-}$glomeruli \\
\hline $\mathrm{A}-1(+/+)$ & 1634 & 654 & 982 \\
\hline$A-2(-1-)$ & 1398 (86\%) & $743(114 \%)$ & $655(67 \%)$ \\
\hline B-1 $(+/+)$ & 1276 & 479 & 797 \\
\hline$B-2(-1-)$ & $941(74 \%)$ & 534 (112\%) & 407 (51\%) \\
\hline$c-1(+/+)$ & 1659 & 817 & 842 \\
\hline$(-2(-1-)$ & 1465 (88\%) & $921(113 \%)$ & $544(65 \%)$ \\
\hline Mice & Total glomeruli & $\mathrm{OCAM}^{+}$glomeruli & OCAM $^{-}$glomeruli \\
\hline $\mathrm{D}-1(+/+)$ & 1599 & 1027 & 572 \\
\hline$D-2(-1-)$ & $1307(82 \%)$ & 746 (73\%) & $561(98 \%)$ \\
\hline $\mathrm{E}-1(+/+)$ & 1807 & 1129 & 678 \\
\hline $\mathrm{E}-2(-1-)$ & $1473(82 \%)$ & $864(77 \%)$ & 609 (90\%) \\
\hline $\mathrm{F}-1(+/+)$ & 1607 & 1070 & 537 \\
\hline $\mathrm{F}-2(-1-)$ & 1339 (84\%) & 841 (79\%) & $498(93 \%)$ \\
\hline
\end{tabular}

uli were NP-1-negative (NP-1 ${ }^{-}$) (Fig. 2C,D) and OCAMpositive $\left(\mathrm{OCAM}^{+}\right)$(Fig. $\left.3 C, D\right)$. These results imply that Sema3A-deficient mice cannot form or maintain a specific subset of glomeruli, whereas they may form NP-1 ${ }^{-}$glomeruli in a manner similar to that in the wild-type mice.

\section{Displacement of NP-1 ${ }^{+}$glomeruli to the anteromedial and ventral regions of the $\mathrm{OB}$}

Figure $2 A, C$ shows two examples of the unrolled and flattened map of NP-1 ${ }^{+}$glomeruli (filled circles) and NP-1 ${ }^{-}$glomeruli (open circles) in the wild-type OB (Nagao et al., 2000). NP-1 ${ }^{+}$ olfactory axons projected selectively to glomeruli within two compartments, the lateral band (Fig. $2 A, L B$ ) and the medial band (Fig. $2 A, M B$ ). NP-1 ${ }^{+}$glomeruli (which receive NP-1 ${ }^{+}$ olfactory axons) were completely excluded from the anteromedial region (open arrowheads) and the ventral region ( filled arrowheads) of the $\mathrm{OB}$, in which Sema3A-expressing ensheathing cells were observed during the developing stages (Crandall et al., 2000; Schwarting et al., 2000).

Figure $2 B, D$ shows two examples of the unrolled map of $\mathrm{NP}-1^{+}$and NP-1 ${ }^{-}$glomeruli in the Sema3A-deficient OBs. In the mutant $\mathrm{OB}(n=7)$, the spatial arrangement of $\mathrm{NP}_{-} 1^{+}$and $\mathrm{NP}-1^{-}$glomeruli was profoundly altered; NP- ${ }^{+}$glomeruli were not confined within the two bands but were spread over the entire $\mathrm{OB}$, including the anteromedial and the ventral regions. The positions of the $\mathrm{P} 2$ glomeruli (which are $\mathrm{NP}-1^{-}$) are indicated by $\mathrm{P} 2$ in the unrolled map of wild-type $\mathrm{OB}$ (Fig. 2C) and Sema3Adeficient $\mathrm{OB}$ (Fig. 2D). Although all of the $\mathrm{P} 2$ glomeruli were located in the ventral NP-1 ${ }^{-}$compartment in the wild-type OB, the $\mathrm{P} 2$ glomeruli in the mutant $\mathrm{OB}$ were located in the ventral region, in which NP-1 ${ }^{+}$glomeruli intermingled with NP-1 ${ }^{-}$glomeruli. These results suggest that in the Sema3A-deficient OB, a number of NP-1 ${ }^{+}$glomeruli are displaced from the NP- $1^{+}$compartments to the more ventral NP-1 ${ }^{-}$compartment. The hypothesis of ventral displacement of a number of NP-1 ${ }^{+}$glomeruli is in agreement with the observation that, although the GL in the ventralmost region of the wild-type $\mathrm{OB}$ is typically one glomerulus thick, a pile-up of two or more glomeruli was found in the ventralmost region of the Sema3A-deficient OB (Fig. 1C,D, arrows).

In the sections labeled with anti-NP-1 antibody, we compared the numbers of $\mathrm{NP}_{-} 1^{+}$and $\mathrm{NP}-1^{-}$glomeruli between the Sema3A-deficient and the wild-type OBs. As listed in Table 1, the number of $\mathrm{NP}^{-} 1^{-}$glomeruli in the Sema3A-deficient OB de- 

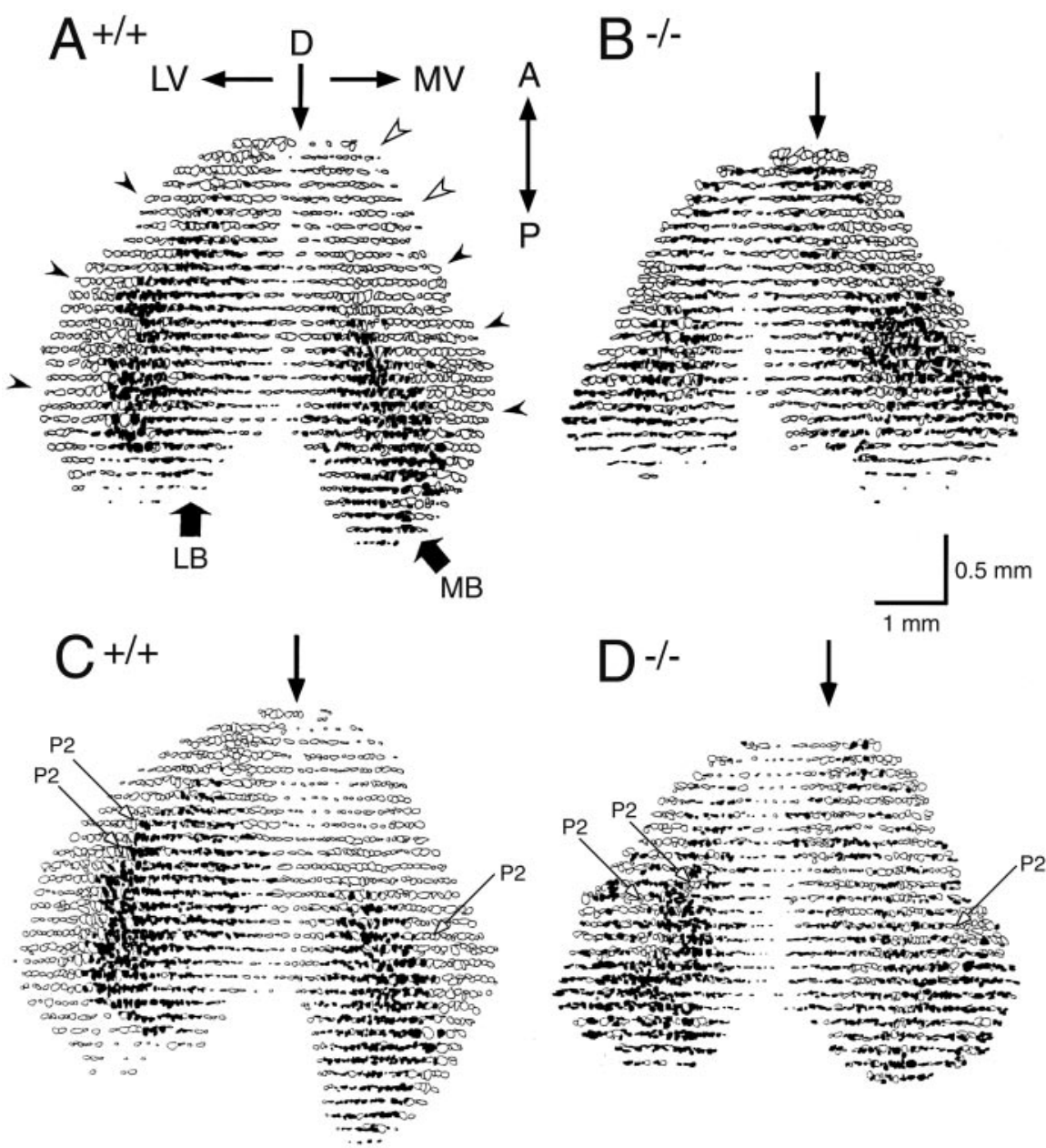

Figure 2. Spatial arrangement of NP-1 ${ }^{+}$and NP-1 ${ }^{-}$glomeruli in the wild-type and Sema3A-deficient OBs. In adult wild-type $\mathrm{OB}(A, C,+/+), \mathrm{NP}-1^{+}$glomeruli ( filled circles) were absent from the ventral region ( $A$, filled arrowheads) and the anteromedial region ( $A$, open arrowheads). NP-1 ${ }^{+}$glomeruli were clustered within two bands, the lateral band $(L B)$ and the medial band $(M B)$. In littermate Sema3A-deficient mice $(B, D,-/-), N P-1^{+}$glomeruli spread over the entire $0 B$, including the ventral region and the anteromedial region. $C, D$, In the left $O B$ of a wild-type mouse $(C$ and that of a littermate Sema3A-deficient mouse $(D), P 2$ glomeruli ( $P 2$, open arrows) were located at approximately similar positions, two $P 2$ glomeruli at the ventrolateral region and one $\mathrm{P} 2$ glomeruli at the ventromedial region. All of the $\mathrm{P} 2$ glomeruli were $\mathrm{NP}-1^{-}$. $A$, Anterior; $P$, posterior; $D$, dorsal; $L V$, lateroventral; $M V$, medioventral.

creased to $61 \pm 9 \%(\mathrm{SD} ; n=3)$ of that of the wild-type $\mathrm{OB}$, whereas the number of $\mathrm{NP}_{-1}{ }^{+}$glomeruli remained unchanged. This suggests that a subset of NP-1 ${ }^{-}$glomeruli is absent in the sensory map of the Sema3A-deficient OB.

\section{Disappearance of a subset of $\mathrm{OCAM}^{+}$glomeruli in the anteromedial region}

OCAM is a cell adhesion molecule expressed by a subset of olfactory axons originating from ventrolateral zones (zones II-IV) of the olfactory epithelium. Olfactory axons from the dorsomedial zone (zone I) of the epithelium do not express OCAM (Yoshihara et al., 1997). Figure $3 A, C$ shows two examples of the unrolled maps of OCAM ${ }^{+}$( filled circles) and $\mathrm{OCAM}^{-}$(open circles) glomeruli in the wild-type OB. OCAM ${ }^{+}$and $\mathrm{OCAM}^{-}$glomeruli showed a largely segregated distribution (Mori et al., 1985). $\mathrm{OCAM}^{-}$glomeruli were distributed in the anterodorsal zone (zone I) of the $\mathrm{OB}$, whereas $\mathrm{OCAM}^{+}$glomeruli were located in the posteroventral zones (zones II-IV) of the OB (Yoshihara et al., 1997). In the unrolled map of the wild-type OB, a group of $\mathrm{OCAM}^{+}$glomeruli was consistently observed to form a tongue- like area (Fig. 3A,C, open arrow) in the anteromedial region of the $\mathrm{OB}$ (Nagao et al., 2000).

In the Sema3A-deficient mice $(n=6)$ (Fig. 3B,D), the overall pattern of the spatial distribution of $\mathrm{OCAM}^{+}$and OCAM glomeruli was similar to that of the wildtype OB. However, the boundary between the $\mathrm{OCAM}^{-}$zone I and OCAM ${ }^{+}$zones II-IV was distorted in the Sema3Adeficient $O B$ such that the sharp segregation of the $\mathrm{OCAM}^{+}$and $\mathrm{OCAM}^{-}$zones typically seen in the wild-type $\mathrm{OB}$ was not apparent in the Sema3A-deficient OB. In addition, the tongue-like area of OCAM ${ }^{+}$ glomeruli was consistently absent in the anteromedial region of the Sema3Adeficient $\mathrm{OB}$ (Fig. 3B,D). In both wildtype and mutant $\mathrm{OBs}$, all of the $\mathrm{P} 2$ glomeruli were located in the $\mathrm{OCAM}^{+}$zone (Fig. 3C,D).

We compared the numbers of $\mathrm{OCAM}^{+}$and $\mathrm{OCAM}^{-}$glomeruli between the Sema3A-deficient and the wildtype OB. The number of $\mathrm{OCAM}^{+}$glomeruli in the Sema3A-deficient $\mathrm{OB}$ decreased to $76 \pm 3 \%$ (SD; $n=3$ ) of that of the wild-type OB. In contrast, the number of OCAM $^{-}$glomeruli remained unchanged (Table 1). This suggests that a subset of $\mathrm{OCAM}^{+}$and NP-1 ${ }^{-}$glomeruli cannot be formed or maintained in the Sema3A-deficient mice.

\section{Displacement of}

molecular-feature domains

The disappearance of $\mathrm{OCAM}^{+}$glomeruli from the anteromedial region and the change in the spatial arrangement of $\mathrm{NP}-1^{+}$glomeruli in the ventral region may indirectly result in the change in the spatial arrangement of glomeruli in other regions of the OB. We examined this possibility by measuring the spatial distribution of odorant-evoked responses from the dorsal region of the $\mathrm{OB}$ using the method of optical recording of intrinsic signals. The imaged dorsal region (Fig. $4 B$, blue dashed line) consisted of $\mathrm{OCAM}^{-}$glomeruli. Most glomeruli in this region were $\mathrm{NP}_{-} 1^{-}$, whereas a small number of NP- $1^{+}$glomeruli were present at the caudolateralmost part of this region. With the optical imaging from the dorsal region of the rat $\mathrm{OB}$, we showed previously that fatty acid odorants selectively activated glomeruli in the dorsomedial domain, whereas aliphatic alcohol and phenol odorants activated glomeruli within the lateral domain (Uchida et al., 2000). In the present study, we compared the positions of the molecular-feature domains between the wild-type OB and the Sema3A-deficient OB.

In all wild-type OBs examined, the fatty acid-responsive domain was consistently observed to extend from the central part to the anterocentral part of the dorsal OB (Fig. $5 A, C, D$, red and pink circles), whereas aliphatic alcohols and phenol invariably activated glomeruli that were located in the lateral domain (Fig. $5 C, D$, blue and green circles). In the wild-type mice, the fatty acids activated an additional cluster of glomeruli in the posteromedial 
part (Fig. 5C,D, arrows) in addition to the anterocentral part of the dorsal OB. Analysis of the spatial arrangement of the fatty acid domains on the unrolled map, together with mapping of odorant-induced zif268 expression, indicated that the two domains formed a pair of symmetrically arranged fatty acid domains (Inaki et al., 2002). The anterocentral fatty acid domain belonged to the lateral map, whereas the posteromedial fatty acid-responsive domain was located in the dorsalmost region of the dorsoventrally elongated fatty acid domain that belonged to the medial map of the OB. The glomeruli in the anterocentral fatty acid domain were NP-1 (data not shown) (Fig. 4B).

Figure $5 E-J$ shows the position of fatty acid-responsive glomeruli and alcohol/ phenol-responsive glomeruli in the Sema3A-deficient mice. As in the wildtype $\mathrm{OB}$, fatty acid-responsive glomeruli formed a domain organization. However, the position of the fatty acid-responsive domain was always altered in the Sema3A-deficient OB (Fig. 5B). The right diagram of Figure $4 A$ summarizes the altered position of the fatty acid-responsive domain in 10 Sema3A-deficient OBs. For comparison, the positions of fatty acid domains in the wild-type $\mathrm{OB}$ are shown by gray dotted lines. In most mutant OBs $(n=8)$, the positions of the fatty acidresponsive domain shifted either to the anterior or to the medial part of the dorsal OB. However, in the remaining two cases the fatty acid-responsive domain shifted to the medioposterior or the lateral part of the dorsal OB. These results indicate that the fatty acid domain tends to shift anteriorly or medially, but the altered positions of the domains differ among different OBs of the Sema3A-deficient mice. It is of interest that in some mutants, the altered positions differed clearly between the right and left OBs of the same mice (Fig. 5F,G,I,J).

In the wild-type $\mathrm{OB}$, a large number of alcohol/phenolresponsive glomeruli consistently formed a cluster in the anterolateral part of the dorsal $\mathrm{OB}$ (lateral domain) (Fig. 5C,D, green and blue circles). This domain extends into the lateral wall of the OB (Johnson et al., 1999; Inaki et al., 2002). The Sema3Adeficient $\mathrm{OB}$ tended to show the alcohol/phenol-responsive domain in the anterolateral part, but the activated domain decreased in areas at varying degrees compared with the wild-type OB. This might be attributable either to the disappearance of some alcohol/phenol-responsive glomeruli in the anterolateral domain or to the dislocation of the domain more lateroventrally to the lateral wall, where the response cannot be detected by the present optical imaging method (Inaki et al., 2002).

\section{Discussion}

Distortion of adult sensory maps in the Sema3A-deficient OB In agreement with a previous study on olfactory axon guidance by Sema3A during embryogenesis (Schwarting et al., 2000), the present results show a profound distortion of the glomerular sensory map in the OB of adult Sema3A-deficient mice. NP-1 ${ }^{+}$glomeruli in the Sema3A-deficient OB spread ectopically into the anteromedial and ventral regions, in which Sema3A is expressed in the wild-type $\mathrm{OB}$ (Fig. 2). These observations demonstrate that the misguidance of the olfactory axons during embryogenesis results in the distorted glomerular maps in the adult $\mathrm{OB}$, suggesting the key role of early olfactory axon guidance in determining the spatial arrangement of glomeruli in the adult $\mathrm{OB}$. The misrouting of $\mathrm{NP}-1^{+}$olfactory axons cannot be adjusted at postnatal and adult stages, despite the continued turnover of the olfactory axons throughout these stages (Graziadei and Graziadei, 1978).

In the wild-type $\mathrm{OB}, \mathrm{NP}-1^{+}$glomeruli are excluded from the Sema3A-positive anteromedial and ventral regions and are confined in the Sema3A-negative medial and lateral bands. During embryogenesis, Sema3A in the anteromedial and ventral regions may repel NP- $1^{+}$olfactory axons from these regions (Schwarting et al., 2000). Sema3A in the anteromedial region may force growing NP-1 ${ }^{+}$olfactory axons to project either more laterally to the lateral band or posteriorly to the medial band. Similarly, Sema3A in the ventral region may force $\mathrm{NP}-1^{+}$axons to project more 
A

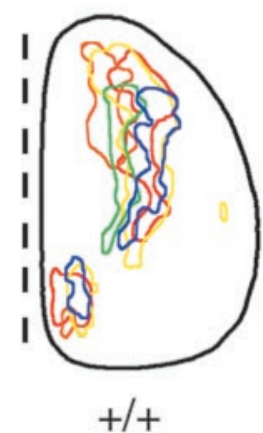

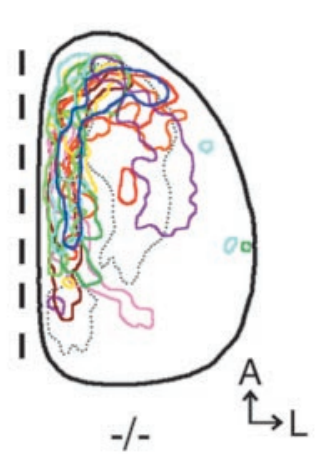

B

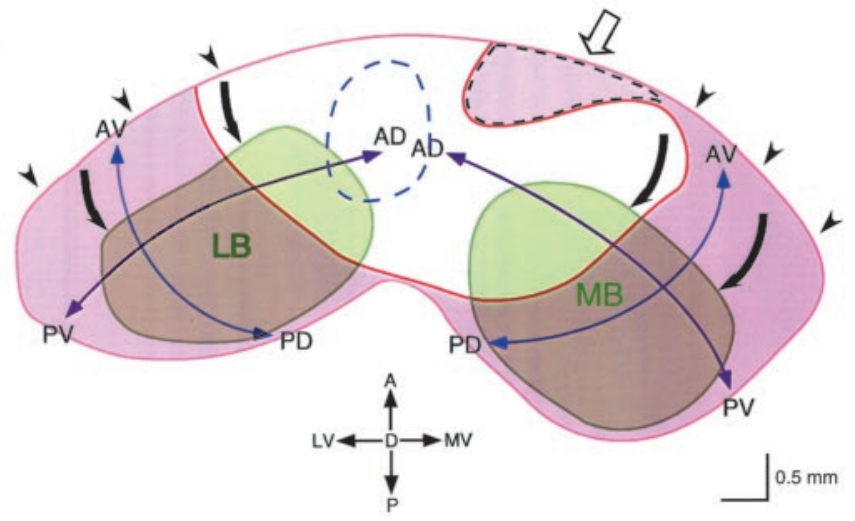

Figure 4. $\quad A_{1}$ Comparison of the positions of the fatty acid-responsive domains between wild-type OBs (left, $+/+$ ) and Sema3A-deficient OBs (right, $-/-$ ). Left, Superimposition of the fatty acid domains (surrounded by colored lines) recorded from the dorsal surface of five different wild-type OBs ( 5 different colors). Right, Positions of the fatty acid-responsive domains recorded from 10 different Sema3A-deficient $\mathrm{OBs}$ (10 different colors). The stereotypical position of the fatty acid domains in the wild-type OB is shown by the dotted lines for comparison. The midline between the left and right $\mathrm{OBs}$ (thick straight dashed lines) was used as a reference line to superimpose the fatty acid-responsive domains. The thick black lines indicate the imaged region on the dorsal $0 \mathrm{~B}$. $B$, Schematic diagram of the flattened left $O B$, illustrating the possible role of Sema $3 A$ in the formation of the olfactory sensory maps. The blue dashed line indicates the region from which we recorded the optical imaging of intrinsic signals. The $0 \mathrm{CAM}^{+}$zones are pink, whereas NP-1 ${ }^{+}$bands are green. In the wild-type mice, $\mathrm{NP}-1^{+}$glomeruli are excluded from the ventral region ( filled arrowheads) and the anteromedial region (open arrow), where Sema $3 \mathrm{~A}$ is expressed. In the Sema $3 \mathrm{~A}-$ deficient $\mathrm{OB}, \mathrm{NP}-1^{+}$glomeruli are spread over the entire $0 \mathrm{~B}$, including the ventral and anteromedial regions. The alteration suggests that Sema3A functions in determining the position of NP-1 ${ }^{+}$glomeruli along the PD-AV axis, pushing them away from the ventral region ( filled arrows). In addition, Sema3A-deficient mice lacked a specific subset of $0 \mathrm{CAM}^{+} / \mathrm{NP}-1^{-}$glomeruli, including those of the tongue-like area (surrounded by a black dashed line and indicated by an open arrow). $A$, Anterior; $L$, lateral; $P$, posterior; $D$, dorsal; $L V$, lateroventral; $M V$, medioventral; $P V$, posteroventral; $A D$, anterodorsal; $L B$, lateral band; $M B$, medial band.

dorsally to either the lateral band or the medial band (Fig. $4 B$ ). In the absence of repellent signals from $\mathrm{Sema} 3 \mathrm{~A}$ in the mutant $\mathrm{OB}$, a subset of NP-1 ${ }^{+}$axons can enter these regions and form ectopic glomeruli there. Thus, the present results indicate that Sema3ANP-1 interaction regulates the spatial arrangement of a subset of glomeruli in the sensory map of adult $\mathrm{OB}$.

\section{Sema3A-NP-1 interaction may function in the glomerular} map formation along the posterodorsal-anteroventral axis In the wild-type rats and mice, individual OBs contain two sensory maps, the lateral and medial maps (Johnson et al., 1999; Nagao et al., 2000). The Sema3A-positive ventral region is located at the boundary between the lateral and medial maps. NP-1 ${ }^{+}$ glomeruli in the lateral band of the lateral map are clearly segregated from $\mathrm{NP}-1^{+}$glomeruli in the medial band of the medial map by the ventral Sema3A-positive region (Fig. 2). This suggests that the ventral Sema3A-expressing region forms a barrier area that segregates the olfactory axons projecting to the lateral map from those projecting to the medial map (Schwarting et al., 2000). Thus, the Sema3A signal is important to form the two sensory maps in segregated parts of the OB (Fig. 4B).

In the unrolled map of the wild-type $\mathrm{OB}$, the ventral boundary of both the lateral and medial bands of NP- $1^{+}$glomeruli is perpendicular to the posterodorsal-anteroventral (PD-AV) axis (Fig. $4 B, P D, A V$ ) (Inaki et al., 2002). The stereotypical spatial arrangement of NP-1 ${ }^{+}$glomeruli within the lateral and medial bands (Figs. 2, 4B) and exclusion of the NP- $1^{+}$glomeruli from the ventral region suggest that the Sema3A-NP-1 interaction plays an important role in the positioning of glomeruli along the $\mathrm{PD}-\mathrm{AV}$ axis. Indeed, the position of glomeruli along the PD-AV axis was strongly distorted in the Sema3A-deficient OB (Fig. 2).

\section{Disappearance of specific subsets of glomeruli}

The Sema3A-deficient OB lacked a subset of NP-1 ${ }^{-}$glomeruli. A group of NP-1 ${ }^{-} / \mathrm{OCAM}^{+}$glomeruli in the tongue-like area in particular (Figs. 3, open arrow, 4B, area surrounded by black dashed line) were consistently absent in the anteromedial region of the Sema3A-deficient OB. This is in agreement with the lack of $\mathrm{OCAM}^{+}$axons in the anteromedial region of the OB of Sema3Adeficient embryos (Schwarting et al., 2000). Thus, a subset of $\mathrm{OCAM}^{+}$olfactory axons cannot project to the anteromedial region during embryogenesis, resulting in the almost complete loss of $\mathrm{OCAM}^{+}$glomeruli in the anteromedial region of the adult Sema3A-deficient OB. Alternatively, Sema3A expressed in the olfactory epithelium and the $\mathrm{OB}$ might affect the generation or survival of a specific subset of olfactory sensory neurons (Giger et al., 1996, 1998; Pasterkamp et al., 1998; Williams-Hogarth et al., 2000).

In the wild-type $\mathrm{OB}$, olfactory axons projecting to the glomeruli in the tongue-like area do not express NP-1 at the level detectable by immunohistochemistry (Fig. 4B). Thus, Sema3A expressed by ensheathing cells in this region during embryogenesis may also play a key role in the formation of a subset of NP-1 ${ }^{-}$glomeruli. Sema3A might exert its effect on the growth cones of specific subsets of the olfactory axons through an as yet unknown receptor other than NP-1 (Delaire et al., 2001). Molecular markers of specific subsets of the olfactory axons (OCAM and NP-1) may provide a good tool for examining in vivo and in vitro the effect of Sema3A on the behavior of the olfactory axon growth cones.

$\mathrm{NP}-1^{-} / \mathrm{OCAM}^{+}$glomeruli in the tongue-like area are susceptible to olfactory nerve transection; even after the reinnervation of a large number of glomeruli, those in the tongue-like area do not re-form (Christensen et al., 2001). Functional roles and response specificity to odorants of glomeruli in the tongue-like area remain unknown.

\section{Alteration in the spatial pattern of odorant-evoked activity}

The disappearance of a specific subset of glomeruli and the displacement of some of the NP- $1^{+}$glomeruli in the Sema3Adeficient $\mathrm{OB}$ resulted in the change in the spatial pattern of odorant-evoked activity (Figs. 4A, 5). Optical imaging of intrinsic signals recorded from the dorsal region of the mutant $\mathrm{OB}$ indicated that individual odorants activated a specific subset of glomeruli, as is the case with the wild-type OB. The two molecularfeature domains (Uchida et al., 2000) were also detected in the Sema3A-deficient OB. However, the fatty acid-responsive domain 
was always displaced (Fig. 5). The alcohol/ phenol-responsive domains were either displaced or decreased in size.

In the Sema3A-deficient mice, the disappearance of a cluster of $\mathrm{NP}^{-1}{ }^{-} / \mathrm{OCAM}^{+}$ glomeruli occurred in the anteromedial region of the $\mathrm{OB}$, and the displacement of the $\mathrm{NP}-1^{+}$glomeruli occurred in the ventral region of the OB. These regions do not overlap with the dorsal region, in which the change in the position of the fatty acidresponsive domain was detected (Fig. 4B). Thus, the alteration in the fatty acid domain may be attributable to the secondary rearrangement of glomeruli after the primary change that occurred in the anteromedial and ventral regions of the OB. The alteration of the sensory map in the dorsal $\mathrm{OB}$ suggests that interactions among glomeruli play an important role in the overall spatial arrangement of glomeruli, as is the case with barrel fields of the rodent somatosensory cortex (Welker and Van der Loos, 1986). The disappearance of a cluster of NP-1 ${ }^{-} / \mathrm{OCAM}^{+}$glomeruli in the anteromedial region may result in a displacement of the remaining glomeruli into the empty space. For example, the medial or anterior shift of the position of the fatty acid domain in the Sema3A-deficient OB can be explained by the displacement of the fatty acid-responsive glomeruli toward the vacated anteromedial region (Figs. 4A, 5).

The displacement of many NP- ${ }^{+}$glomeruli into the ventral region is in agreement with the tendency of more glomeruli in the ventral region of the Sema3Adeficient mice (Figs. 1, 2). Displacement of the NP-1 ${ }^{+}$glomeruli into the ventral region may indirectly cause a displacement of more dorsally located glomeruli to the ventral direction. Thus, the number of glomeruli tended to decrease from the dorsal surface of the Sema3A-deficient OB.

In striking contrast to the stereotypical position of the fatty acid domain in the wild-type $\mathrm{OB}$, the altered position of the fatty acid domain in the mutant $\mathrm{OB}$ varied among different $\mathrm{OBs}$, and even between right and left OBs of the same mice (Fig. 5). This suggests that in the absence of Sema3A, the molecular-feature domains can be formed, but the positions of the domains are not determined in a strict way.

The change in the glomerular sensory map and the odorantevoked response map in the Sema3A-deficient OB may accompany the change in the function of the $\mathrm{OB}$. Thus, it is of great interest to examine the change in the behavior of the Sema3A-deficient mice in response to the olfactory stimuli. However, the Sema3A-deficient mice showed an additional alteration in the structure of the olfactory cortex (M. Taniguchi, unpublished data). Thus, to examine the behavioral change that accompanies the alteration in the sensory map of the OB, it is necessary to delete the Sema3A selectively in the OB.

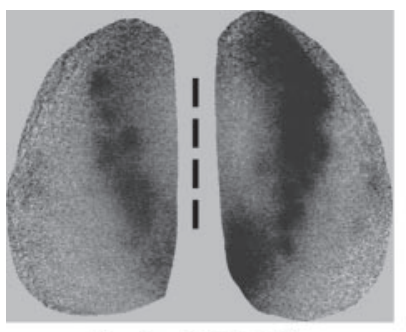

$\mathrm{A}+/+5 \mathrm{COOH}$


E -/-

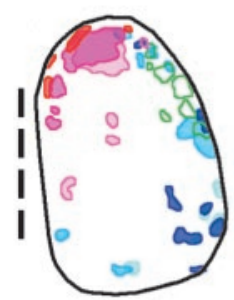

$\mathrm{H}-/-$

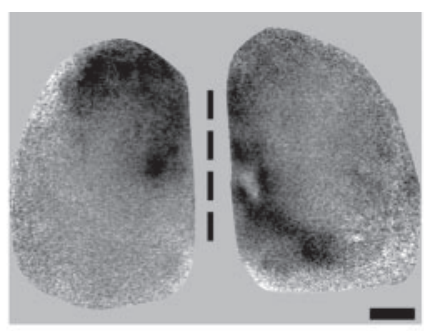

B - $/-5 \mathrm{COOH}$
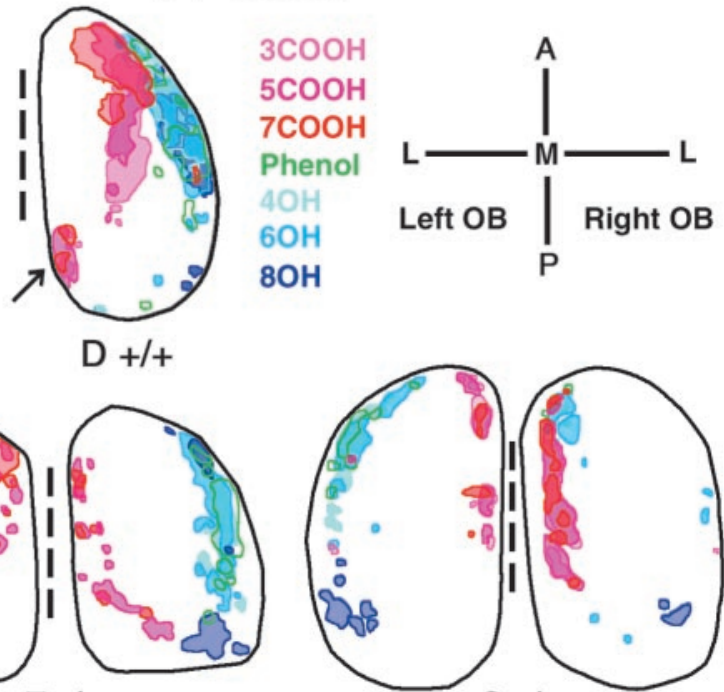

F -/-

G -/-
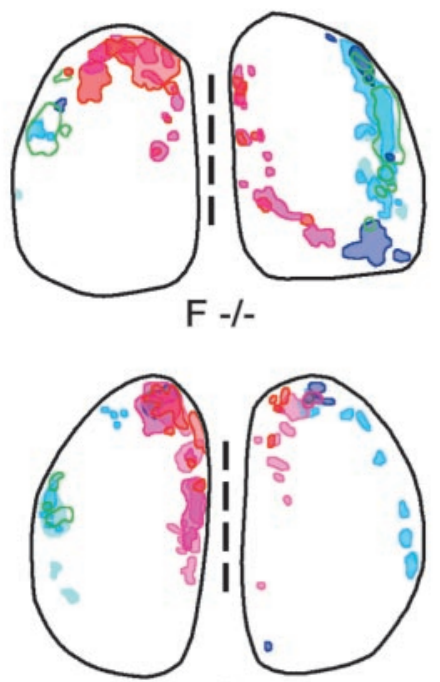

I -/-

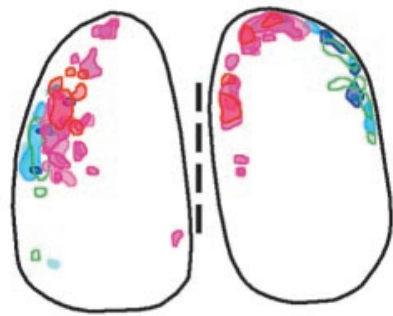

$\mathrm{J}-/-$

Figure 5. Optical imaging of intrinsic signals in response to odorant stimulation recorded from the dorsal surface of the $O B$ of adult wild-type and Sema3A-deficient mice. $A, B$, Spatial distribution of the response to valeric acid $(5 \mathrm{COOH})$ stimulation recorded from the right and left $\mathrm{OBs}$ in an adult wild-type mouse $(A,+/+)$ and a Sema3A-deficient mouse $(B,-/-) .(-J$, Spatial distribution of the optically recorded intrinsic signals in response to a homologous series of fatty acids and aliphatic alcohols. The areas of the activated glomeruli are enclosed by the colored circles. ( and D show the fatty acid- (red), phenol- ( green), and liphatic alcohol- (blue) responsive domains in two different adult wild-type mice, whereas $E-J$ show these domains in six different Sema3A-deficient mice. In the wild-type mice, the fatty acid-responsive domains were consistently observed at the anterocentral part of the dorsal OB. Fatty acids also activated a cluster of glomeruli at the posteromedial part ( $C, D$, arrows). in the spatial arrangement of the fatty acid-, aliphatic alcohol-, and phenol-responsive domains. Dashed lines represent the midline separating the left and right $\mathrm{OBs}$. Scale bar, $500 \mu \mathrm{m} .3 \mathrm{COOH}$, Propionic acid; $7 \mathrm{COOH}$, heptylic acid; $40 \mathrm{H}$, butyl alcohol; $60 \mathrm{H}$, hexyl alcohol; $80 \mathrm{H}$, octyl alcohol; $A$, anterior; $L$, lateral; $P$, posterior; $M$, medial.

\section{References}

Buck LB (1996) Information coding in the vertebrate olfactory system. Annu Rev Neurosci 19:517-544.

Chisholm A, Tessier-Lavigne M (1999) Conservation and divergence of axon guidance mechanisms. Curr Opin Neurobiol 9:603-615.

Christensen MD, Holbrook EH, Costanzo RM, Schwob JE (2001) Rhinotopy is disrupted during the re-innervation of the olfactory bulb that follows transection of the olfactory nerve. Chem Senses 26:359-369.

Crandall JE, Dibble C, Butler D, Pays L, Ahmad N, Kostek C, Püschel AW, Schwarting GA (2000) Patterning of olfactory sensory connections is mediated by extracellular matrix proteins in the nerve layer of the olfactory bulb. J Neurobiol 45:195-206. 
Delaire S, Billard C, Tordjman R, Chédotal A, Elhabazi A, Bensussan A, Boumsell L (2001) Biological activity of soluble CD100. II. Soluble CD100, similarly to H-SemaIII, inhibits immune cell migration. J Immunol 166:4348-4354.

Giger RJ, Wolfer DP, De Wit GMJ, Verhaagen J (1996) Anatomy of rat semaphorin III/collapsin-1 mRNA expression and relationship to developing nerve tracts during neuroembryogenesis. J Comp Neurol 375:378-392.

Giger RJ, Pasterkamp RJ, Heijnen S, Holtmaat AJGD, Verhaagen J (1998) Anatomical distribution of the chemorepellent semaphorin III/ collapsin- 1 in the adult rat and human brain: predominant expression in structures of the olfactory-hippocampal pathway and the motor system. J Neurosci Res 52:27-42.

Graziadei PPC, Graziadei GAM (1978) The olfactory system: a model for the study of neurogenesis and axon regeneration in mammals. In: Neuronal plasticity (Cotman CW, ed), pp 131-153. New York: Raven.

He Z, Tessier-Lavigne M (1997) Neuropilin is a receptor for the axonal chemorepellent semaphorin III. Cell 90:739-751.

Inaki K, Takahashi YK, Nagayama S, Mori K (2002) Molecular feature domains with posterodorsal-anteroventral polarity in the symmetrical sensory maps of the mouse olfactory bulb: mapping of odorant-induced Zif268 expression. Eur J Neurosci 15:1563-1574.

Johnson BA, Woo CC, Hingco EE, Pham KL, Leon M (1999) Multidimensional chemotopic responses to $\mathrm{N}$-aliphatic acid odorants in the rat olfactory bulb. J Comp Neurol 409:529-548.

Kawakami A, Kitsukawa T, Takagi S, Fujisawa H (1996) Developmentally regulated expression of a cell surface protein, neuropilin, in the mouse nervous system. J Neurobiol 29:1-17.

Kitsukawa T, Shimizu M, Sanbo M, Hirata T, Taniguchi M, Bekku Y, Yagi T, Fujisawa H (1997) Neuropilin-semaphorin III/D-mediated chemorepulsive signals play a crucial role in peripheral nerve projection in mice. Neuron 19:995-1005.

Kobayashi H, Koppel AM, Luo Y, Raper JA (1997) A role for collapsin-1 in olfactory and cranial sensory axon guidance. J Neurosci 17:8339-8352.

Kolodkin AL, Levengood DV, Rowe EG, Tai Y-T, Giger RJ, Ginty DD (1997) Neuropilin is a semaphorin III receptor. Cell 90:753-762.

Luo Y, Raible D, Raper JA (1993) Collapsin: a protein in brain that induces the collapse and paralysis of neuronal growth cones. Cell 75:217-227.

Mombaerts P (1999) Seven-transmembrane proteins as odorant and chemosensory receptors. Science 286:707-711.

Mombaerts P, Wang F, Dulac C, Chao SK, Nemes A, Mendelsohn M, Edmondson J, Axel R (1996) Visualizing an olfactory sensory map. Cell 87:675-686.

Mori K, Fujita SC, Imamura K, Obata K (1985) Immunohistochemical study of subclasses of olfactory nerve fibers and their projections to the olfactory bulb in the rabbit. J Comp Neurol 242:214-229.

Mori K, Nagao H, Yoshihara Y (1999) The olfactory bulb: coding and processing of odor molecule information. Science 286:711-715.
Nagao H, Yoshihara Y, Mitsui S, Fujisawa H, Mori K (2000) Two mirrorimage sensory maps with domain organization in the mouse main olfactory bulb. NeuroReport 11:3023-3027.

Nakamura F, Kalb RG, Strittmatter SM (2000) Molecular basis of semaphorin-mediated axon guidance. J Neurobiol 44:219-229.

Pasterkamp RJ, De Winter F, Holtmaat AJGD, Verhaagen J (1998) Evidence for a role of the chemorepellent semaphorin III and its receptor neuropilin-1 in the regeneration of primary olfactory axons. J Neurosci 18:9962-9976.

Raper JA (2000) Semaphorins and their receptors in vertebrates and invertebrates. Curr Opin Neurobiol 10:88-94.

Royal SJ, Key B (1999) Development of P2 olfactory glomeruli in P2 internal ribosome entry site-tau-LacZ transgenic mice. J Neurosci 19:9856-9864.

Schaefer ML, Finger TE, Restrepo D (2001) Variability of position of the P2 glomerulus within a map of the mouse olfactory bulb. J Comp Neurol 436:351-362.

Schwarting GA, Kostek C, Ahmad N, Dibble C, Pays L, Püschel AW (2000) Semaphorin $3 \mathrm{~A}$ is required for guidance of olfactory axons in mice. J Neurosci 20:7691-7697.

Semaphorin Nomenclature Committee (1999) Unified nomenclature for the semaphorins/collapsins. Cell 97:551-552.

Shepherd GM, Greer CA (1998) Olfactory bulb. In: Synaptic organization of the brain (Shepherd GM, ed), pp 159-203. New York: Oxford UP.

Taniguchi M, Yuasa S, Fujisawa H, Naruse I, Saga S, Mishina M, Yagi T (1997) Disruption of semaphorin III/D gene causes severe abnormality in peripheral nerve projection. Neuron 19:519-530.

Uchida N, Takahashi YK, Tanifuji M, Mori K (2000) Odor maps in the mammalian olfactory bulb: domain organization and odorant structural features. Nat Neurosci 3:1035-1043.

Valverde F, Santacana M, Heredia M (1992) Formation of an olfactory glomerulus: morphological aspects of development and organization. Neuroscience 49:255-275.

Wang F, Nemes A, Mendelsohn M, Axel R (1998) Odorant receptors govern the formation of a precise topographic map. Cell 93:47-60.

Welker E, Van der Loos H (1986) Quantitative correlation between barrelfield size and the sensory innervation of the whiskerpad: a comparative study in six strains of mice bred for different patterns of mystacial vibrissae. J Neurosci 6:3355-3373.

Williams-Hogarth LC, Puche AC, Torrey C, Cai X, Song I, Kolodkin AL, Shipley MT, Ronnett GV (2000) Expression of semaphorins in developing and regenerating olfactory epithelium. J Comp Neurol 423:565-578.

Yoshihara Y, Kawasaki M, Tamada A, Fujita H, Hayashi H, Kagamiyama H, Mori K (1997) OCAM: a new member of the neural cell adhesion molecule family related to zone-to-zone projection of olfactory and vomeronasal axons. J Neurosci 17:5830-5842. 